\title{
Statistical modeling of seasonal wastewater inflows based on periodogram technique: a case study for Kuwait
}

\author{
J. Almedeij \& R. Aljarallah \\ Civil Engineering Department, Kuwait University, Safat, Kuwait
}

\begin{abstract}
This study investigates the variation patterns of monthly wastewater inflow data collected from the active treatment plants in Kuwait for a time period from 1999 to 2009. An attempt to examine the relation with seasonal population variation is achieved indirectly by correlating monthly-total inflow data with climatological parameters of monthly-average temperature and -total rainfall. The periodograms of the inflow, temperature and rainfall data are also determined. The results reveal two significant periodicities of 6 and 12 months. The reason for the existence of these periodicities is explained rationally and a time series model is developed which can be used to set a management plan securing nonconventional water supply for the country.
\end{abstract}

Keywords: water scarcity; nonconventional supply; periodogram; sinusoidal model.

\section{Introduction}

Kuwait is a desert country facing a water shortage problem. Essentially, only one conventional water resource exists, groundwater, with relatively limited quantities. The limited groundwater quantities in Kuwait is due to the few areas of actual surface water runoff and accumulation as evaporation always exceeds available precipitation [1]. Fresh groundwater is found in the depressions of Rawdatain and Umm Al-Aish, which are located in the northern. The freshwater of Rawdatain is kept as a reserve and some amount is marketed as bottled mineral water, while the water of Umm Al-Aish has been contaminated from massive crude oil spillage by the retreating Iraqi army during the 1990 Gulf War. Brackish water exists in Kuwait group and dammam aquifers, stretching east of 
the Arabian Peninsula and slightly sloping towards the Arabian Gulf. This water is used mainly for irrigation and household purposes [2], although using brackish water for irrigation causes deterioration of soil and is not an ideal plan for sustainable agriculture.

Nonconventional water resources have become important in helping overcome the existing water shortage problem in Kuwait. Two alternatives have been employed: seawater desalination, and wastewater treatment and reuse. Multi-stage flash, which suffers from high operation cost and environmental issues [3], is the seawater desalting method used in Kuwait to produce a suitable resource for unlimited potable water quantities. The other nonconventional water resource is wastewater treatment. Wastewater is the only water resource that does not become scarcer with population growth and increases in per capita consumption. The cost of wastewater treatment is also lower than the cost of seawater desalination [4]. A challenging problem though is to explain the seasonal variation pattern of wastewater inflows during the year and provide a forecast of future records for possible potential usage.

\section{Wastewater treatment plants in Kuwait}

Wastewater treatment is managed in Kuwait by the Ministry of Public Works (MPW). Wastewater inflow is currently treated at four Wastewater Treatment Plants (WWTPs): Jahra, Riqqa, Um Al Haiman, and Sulaibia. Figure 1 shows the locations of these plants, and table 1 presents the capacity information. At Jahra, Riqqa and Um Al Haiman plants, the sewage is treated by primary, secondary and tertiary processes with high disinfection levels. Secondary and tertiary treatment include extended aeration activated sludge, filtration, and chlorine as well as UV disinfection in the case of Um Al Haiman. As can be seen in table 1, the latter plant has a relatively very low capacity, but it will be expanded to cover new residential areas assigned by the government south of Kuwait City. Due to capacity limitation, a plan was also set to replace both Jahra and Riqqa with a new plant of Kabd and Um Al Haiman after expansion, respectively. At Sulaibia plant, the inflow is treated through the application of advanced treatment processes to the level of ultra-filtration and reverse osmosis (RO). This plant reached its treatment capacity and is also planned for expansion, which makes the project by far the world's largest membrane-based water reuse facility.

Table 1: Capacity information of active wastewater treatment plants in Kuwait.

\begin{tabular}{cccccc}
\hline & \multicolumn{5}{c}{ Active Treatment Plants } \\
\cline { 2 - 6 } Characteristics & Jahra & Riqqa & Um Al & Sulaibia & Kabd \\
Operation year & 1982 & 1982 & 2001 & 2002 & 2010 \\
\hline Initial capacity $\left(\mathrm{X} 10^{3} \mathrm{~m}^{3} / \mathrm{d}\right)$ & 65 & 85 & 27 & 425 & 180 \\
Current capacity $\left(\mathrm{X} 10^{3} \mathrm{~m}^{3} / \mathrm{d}\right)$ & 65 & 180 & 27 & 425 & - \\
Expansion capacity $\left(\mathrm{X} 10^{3} \mathrm{~m}^{3} / \mathrm{d}\right)$ & - & - & 500 & 600 & - \\
\hline
\end{tabular}




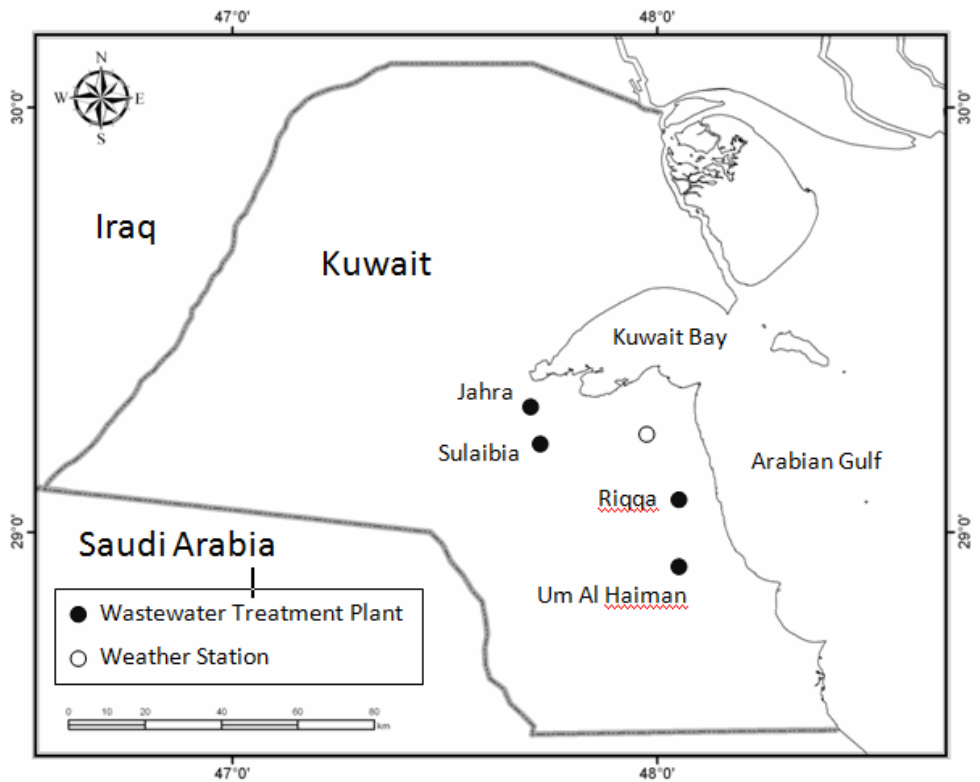

Figure 1: $\quad$ Location of active wastewater treatment plants in Kuwait.

\section{Components of inflows series}

Monthly inflow measurements collected from the WWTPs in Kuwait are used here to examine the relation with climatological parameters of temperature and rainfall. The temperature and rainfall data were obtained by the Metrological Department of the Directorate General of Civil Aviation from a weather station located in Kuwait Airport (see fig. 1). A plot of monthly-totaled inflow data for the period from 1999 to 2009 is explored in fig. 2. This range of data represents the most accurate records available in MPW. As seen in fig. 2, two main components of time series are recognized: long-term trend and short-term seasonality. The long-term trend of wastewater inflows is increasing linearly with time mainly due to population growth. As reported by the Public Authority for Civil Information, the population in Kuwait increased linearly from about 2 to 3.5 Million for this time period. The second component of time series is a short-term seasonality. This component observed in the inflow data is more complicated than the long-term trend. It is important to remove the long-term trend component from the data to study the short-term seasonality behavior more clearly. This is achieved by subtracting the equation of the long-term trend from the overall inflow data.

$$
y=112258 t+10^{7}
$$

where $y=$ trend component of wastewater inflow; and $t=$ time elapsed in the months since January 1999. In this way, the detrended inflow data will have a mean value equal to zero. 


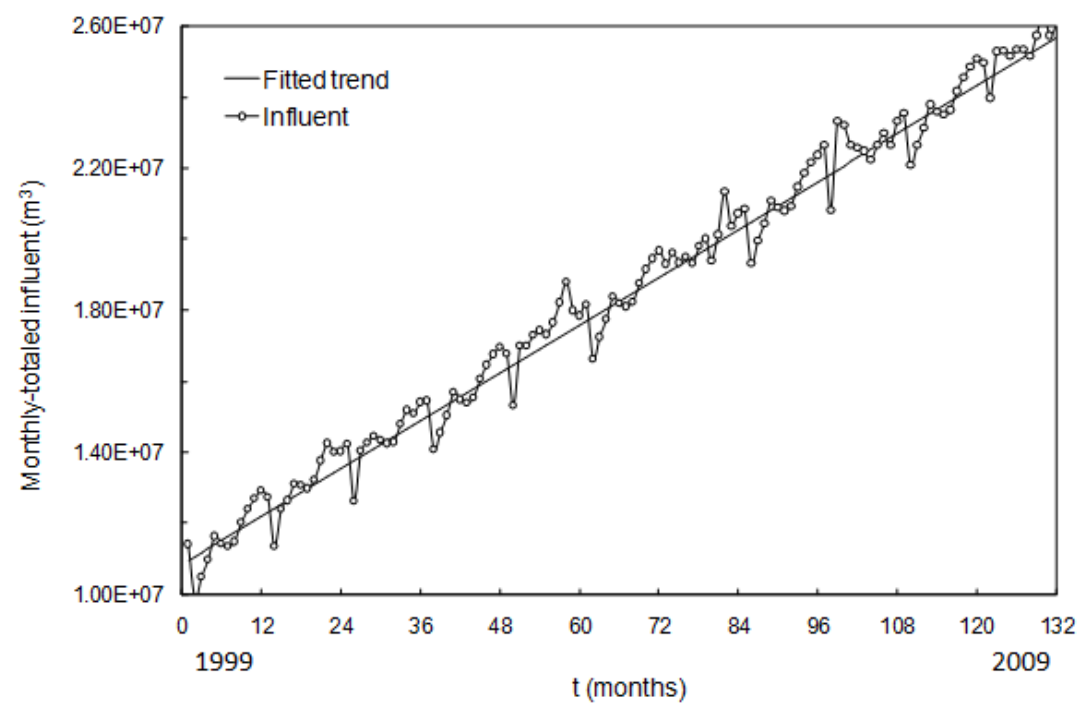

Figure 2: $\quad$ Monthly-totaled inflow data for a time period from January 1999 to December 2009.

Fig. 3 shows the variation of the detrended inflow with monthly-averaged temperature and -totaled rainfall series, both of which were obtained for the same time duration. As can be seen, although the plotted data exhibit a complicated behavior for the given time duration, a possible correlation can be observed in specific months. This correlation can better be described graphically by considering statistics on a seasonal basis. The seasonal mean for the three data sets of detrended wastewater inflow, temperature and rainfall can be obtained by using the expression

$$
J=\frac{1}{N} \sum_{i=1}^{N} j_{i, \tau}, \quad \tau=1, \ldots, 12
$$

where $j=$ seasonal time series, defined as the average for month $\tau$ in the given year $i ; J=$ seasonal mean; and $N=$ total number of years. The results are shown in fig. 4.

The seasonal mean variation for the monthly series of detrended inflow can be explained here. It is observed that the inflow is low in February, June, July, August and September, for the months considered holidays in Kuwait. The Spring break is two weeks starting from the beginning of February, and the Summer break is three months starting from the mid of June. During the time from mid January, two weeks before the Spring break, the weather is typically pleasant and people start going to private farms northern and southern Kuwait and desert camping trips for social gathering where no sanitary networks are available. Some people remain during the day time and return home in the night, while others prefer staying there over the entire break. From mid June to mid September, during the Summer break, many people travel outside Kuwait escaping from the hot weather or visiting relatives and friends. Some of them 

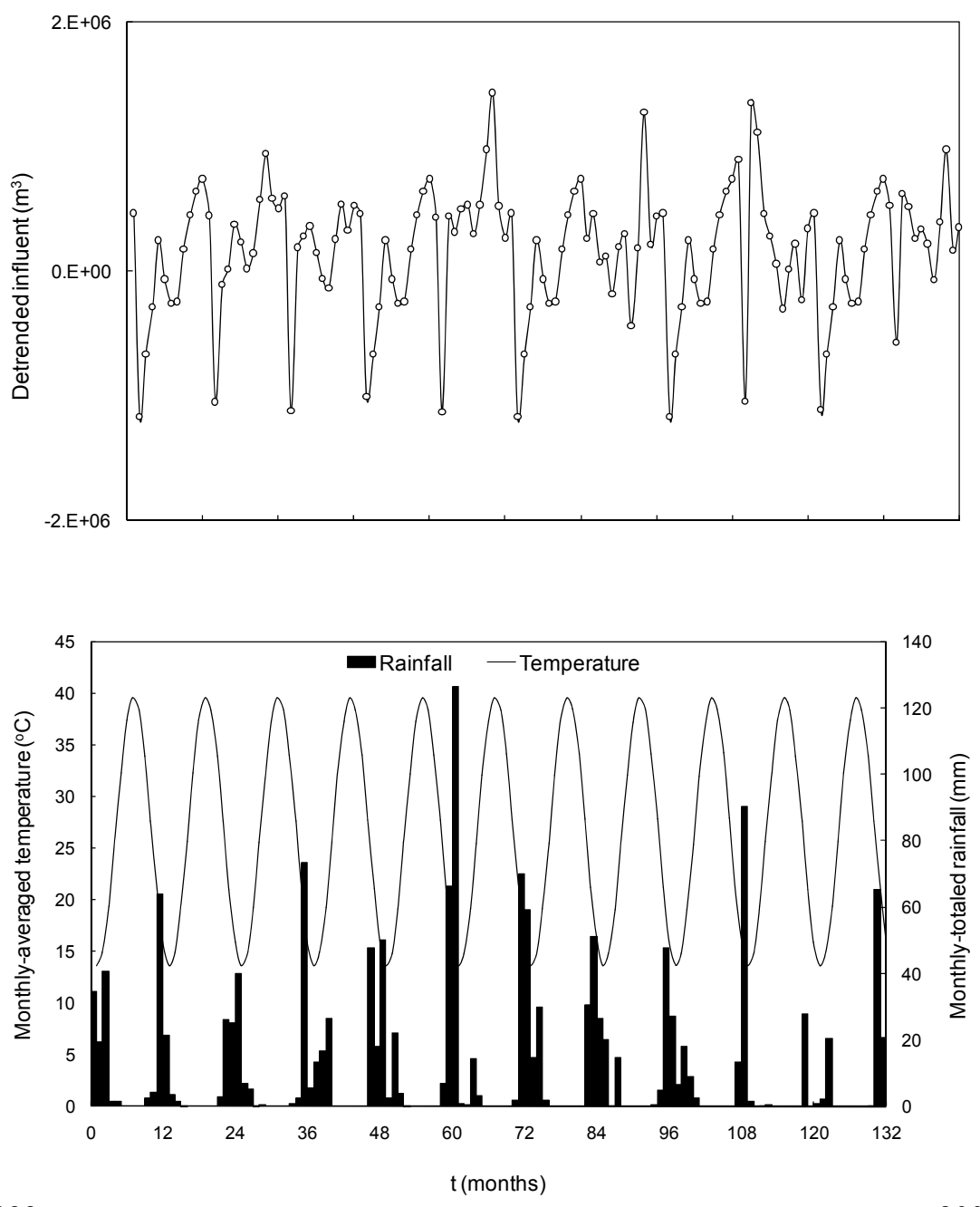

1999

2009

Figure 3: Variation of detrended inflow, monthly-averaged temperature, and monthly-totaled rainfall for a time period from January 1999 to December 2009. The climatological data were obtained from a weather station located in Kuwait Airport.

start coming back from the beginning of September to avoid high traffic in transportation noticed at the end of the break. Fig. 4 also shows that the inflow starts increasing in the months of March and April due to temperature rise as water consumption increases among people and it reaches its peak in May. In the months of October, November, December and January, the inflow rises mainly due to rainfall events. The presence of these amounts of rain in the inflow data is 
due to the illegal connection of storm sewers into sanitary networks by many residents in their houses.

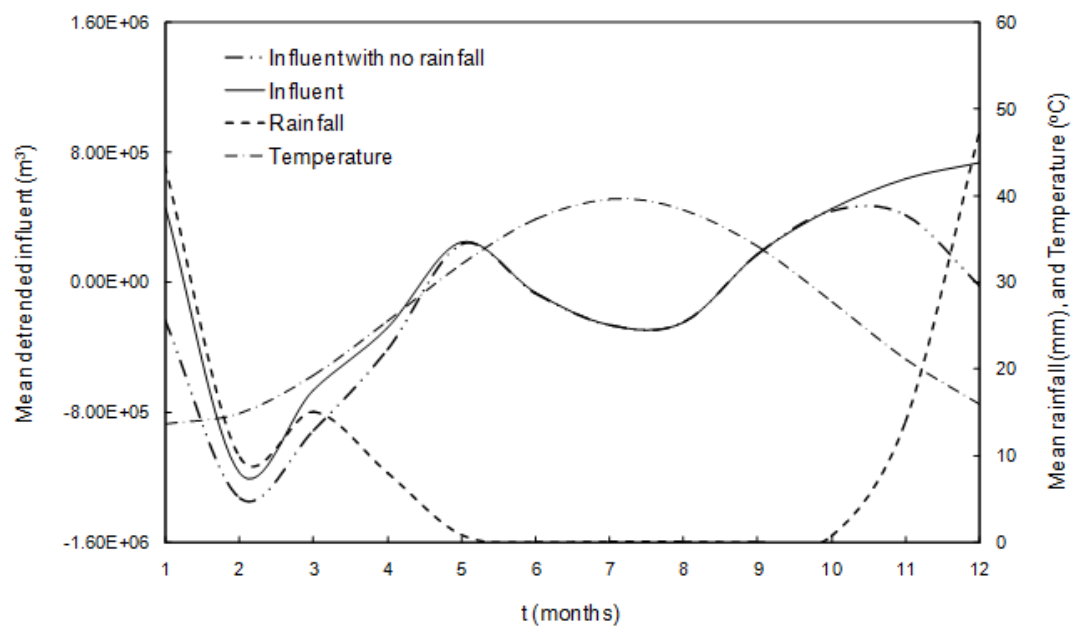

Figure 4: Seasonal mean for the detrended inflow, monthly averaged temperature, and monthly-totaled rainfall.

\section{Periodic behavior}

The relationship between the inflow variation and climatologic parameters deduced from the seasonal mean analysis may be supported further by examining the periodic behavior of the inflow, rainfall, and temperature data. The periodic behavior typically detects the frequencies that are most responsible for the data pattern which can be obtained using the periodogram technique, an unsmoothed spectral plot for examining the cyclic structure in frequency domain [5]. For the periodogram, a large peak value corresponds to a periodicity that is strongly represented in the time series. Fig. 5 provides the periodogram of the inflow data together with that of temperature and rainfall.

The periodogram for the inflow data was estimated for both cases, with and without rainfall contribution (figs. $5 \mathrm{a}$ and $5 \mathrm{~b}$, respectively). Both periodograms depict a complicated pattern with two significant periodicities. For the inflow data with rainfall contribution (fig. 5a), the 12-month period is related to the annual variation of temperature and rainfall events typically observed in climatological data. This is evident, given that the same 12-month period exists in the periodograms of rainfall and temperature (figs. $5 \mathrm{c}$ and $5 \mathrm{~d}$, respectively). Another period of 6-month found in the inflow data exists in rainfall pattern. The 6-month period here is more significant than the 12-month period, while it is not the case in the rainfall data. In the inflow data, the 6-month period resulted from 

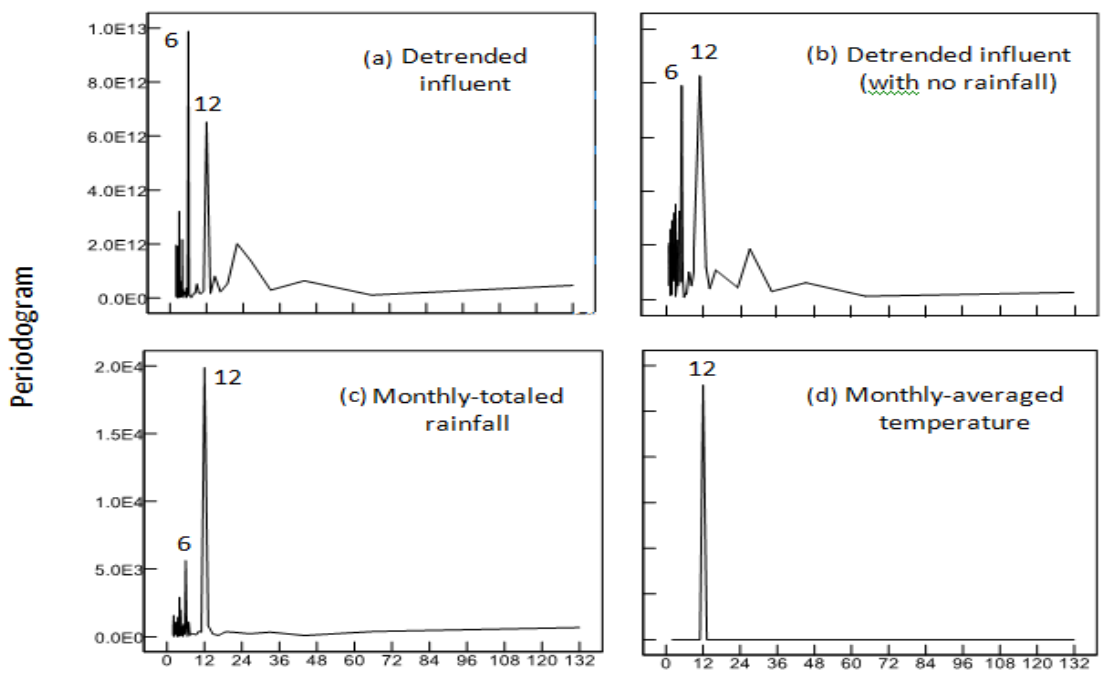

Period (months)

Figure 5: Periodograms for the detrended inflow, monthly-averaged temperature and monthly-totaled rainfall data.

rainfall amounts discharged through the illegal connection of storm sewers into the sanitary networks, as well as from the typical variation of the four seasons of the year during which the mode of people for watering activities or travel plans may change on average. The latter cause is emphasized by the assigned holidays by the government such as the Spring and Summer breaks. In the rainfall data, the 6-month period is less significant than the 12-month, because the characteristics of the four seasons in the arid environment of Kuwait are not distinct. That is, the year in Kuwait can be classified, on average, into rainy and dry months, rather than into four seasons of Spring, Summer, Autumn, and Winter. It is worth noting that the periodogram of inflow data with no rainfall contribution (fig. 5b) shows rather nearly equivalent two periods of 6 and 12 months. Here, this periodogram explains mainly the relation with temperature data as well as the mode of people during the different seasons. Though other periodicities are present in both inflow periodograms, they are not visible in the plot of temperature and rainfall. This is not a surprising result because of the presence of other prevailing factors that may have possible influence on inflow data variation.

\section{Model formulation and forecast}

A possible application for examining the periodic behavior of the inflow data is to provide means of employing the detected periodicities for forecasts. In general, a time-based data containing a periodic sinusoidal component with a 
known wavelength can be modeled using Fourier series, which can be expressed for multi periods as

where

$$
s(t)=\sum_{n=1}^{\infty} \sum_{i=1}^{k} R_{n, i} \cos \left(2 n \pi f_{i} t+\theta_{n, i}\right)
$$

$$
\begin{gathered}
R_{n, i}=\sqrt{a_{n, i}^{2}+b_{n, i}^{2}} \\
\theta_{n, i}=\tan ^{-1}\left(-\frac{b_{n, i}}{a_{n, i}}\right) \\
a_{n, i}=2 f_{i} \int_{L_{i}}^{L_{i}+\frac{1}{f_{i}}} \mathrm{f}(x) \cos \left(2 n \pi f_{i} t\right) d x \\
b_{n, i}=2 f_{i} \int_{L_{i}}^{L_{i}+\frac{1}{f_{i}}} \mathrm{f}(x) \sin \left(2 n \pi f_{i} t\right) d x
\end{gathered}
$$

where $s=$ periodic sinusoidal component of inflow; $R=$ amplitude of variation; $f=$ frequency, equal to the inverse of period; $\theta=$ phase angle; and $k=$ total number of periodicities. The term $(2 n \pi f t+\theta)$ is measured in radians. As determined from the data, $k$ value is equal to two, and the values of $f$ may be set by the periodic nature of inflow data, i.e., $f_{1}=1 / 6$ and $f_{2}=1 / 12$ cycles per month. The phase angle, $\theta$, is necessary to adjust the model so that the cosine function crosses the mean, which is equal to zero for the detrended data, at the appropriate time $t$. The difficulty is to determine analytically the function $\mathrm{f}(x)$ in Fourier coefficients. However, owing to the existing randomness in the data, a more simple procedure can be followed by determining the values $\theta_{n, i}$ and $R_{n, i}$ by means of numerical optimization. Since the above equation will not be solved analytically, it is convenient to reduce the number of fitting coefficients. This may be achieved by testing a number of $s(t)$ models by assuming different values of $n$. Based on Fourier procedure, higher model accuracy is obtained by selecting larger $n$ value. In this case, however, higher model accuracy would result with a more complicated model form. Once $s(t)$ is selected, the overall model including the trend of Equation (1) can be expressed by

$$
h(t)=y(t)+s(t)+\varepsilon(t)
$$

where $h=$ overall inflow; and $\varepsilon=$ error term. The error term, $\varepsilon$, represents the remaining stochastic component of time series free from the non-stationary trend and periodicity, and it is usually taken to be sufficiently stationary in simple time series models. To evaluate specifically the two systematic components, the trend and the periodic, $\varepsilon$ is also assumed to be uncorrelated random variable with zero mean. Based on this, the performance of the model can be tested.

Table 2 shows a comparison for different $s(t)$ models up to $n=4$ for the total detrended inflow data considering rainfall contribution. The criterion of model selection considered here is based on the Mean Absolute Error (MAE).

$$
M A E=\frac{\sum_{i=1}^{N}\left|h_{\text {iobservation }}-h_{\text {icalculation }}\right|}{N}
$$


Table 2: Coefficients and accuracy for selected $s(t)$ models for total detrended inflow data considering rainfall contribution.

\begin{tabular}{cccc|cc|cc|cc}
\hline & \multicolumn{8}{c|}{ Model Order, $n$} \\
\cline { 2 - 10 }$n$ & $i$ & $R_{n, i}$ & $\theta_{n, i}$ & $R_{n, i}$ & $\theta_{n, i}$ & $R_{n, i}$ & $\theta_{n, i}$ & $R_{n, i}$ & $\theta_{n, i}$ \\
\cline { 2 - 9 } & & 400000 & -18 & 400000 & -18 & 400000 & -18 & 400000 & -18 \\
1 & 2 & 400000 & 38.8 & 400000 & 38.8 & 400000 & 38.8 & 400000 & 38.8 \\
2 & 1 & & & 88000 & -0.9 & 88000 & -0.9 & 88000 & -0.9 \\
2 & 2 & & & 47000 & -0.6 & 47000 & -0.6 & 47000 & -0.6 \\
3 & 1 & & & & & -340600 & -1.2 & -340600 & -1.2 \\
3 & 2 & & & & & 220000 & -1 & 220000 & -1 \\
4 & 1 & & & & & & & -33000 & -1.6 \\
4 & 2 & & & & & & & -33000 & 1.5 \\
\hline MAE* & 306,857 & 289,478 & 243,535 & 238,411 \\
\hline
\end{tabular}

*Mean Absolute Error with accuracy measurement in terms of cubic meter, $\mathrm{m}^{3}$.

The range of detrended data until December 2007, with 108 monthly measurements, was used to fit the models, while the remaining data of 24 measurements were used to perform model verification. Compared to the $1^{\text {st }}$ order model $(n=1)$, the $3^{\text {rd }}$ order model $(n=3)$ has better accuracy than the $2^{\text {nd }}$ order model $(n=2)$, with improvement in calculations of $20.6 \%$ and $56.7 \%$, respectively. It is also apparent that the model of the $3^{\text {rd }}$ order is not that difference in terms of accuracy to the model of the $4^{\text {th }}$ order, but it has shorter expression. Accordingly, this study has chosen the model of the $3^{\text {rd }}$ order to represent the detrended inflow data with the following expression.

$$
\begin{gathered}
s(t)=400000 \cos \left(\frac{2 \pi t}{6}-18\right) \\
+400000 \cos \left(\frac{2 \pi t}{12}+38.8\right)+88000 \cos \left(\frac{4 \pi t}{6}-0.9\right) \\
+47000 \cos \left(\frac{4 \pi t}{12}-0.6\right)-340600 \cos \left(\frac{6 \pi t}{6}-1.2\right) \\
+220000 \cos \left(\frac{6 \pi t}{12}-1\right)
\end{gathered}
$$

\section{Conclusions}

This study has revealed the possibility of employing readily available climatological data of temperature and rainfall to investigate indirectly the relation between the seasonal variation pattern of wastewater inflows in Kuwait and the population connected to the sanitary network. The seasonal inflow pattern is relatively complicated reflecting the changing mode of people for watering or travel activities during the year. The periodic analysis for the seasonal inflow data detected two main periods of 6 and 12 months that can 
possibly be interpreted based on the currently available information. The periods have been employed to develop a sinusoidal model that is more efficient than the classical linear regression trend. The discrepancy in the calculations has resulted from the existing complexity in seasonal inflow pattern, which is also exhibited in the corresponding periodogram showing relatively many peaks that are difficult to interpret.

\section{Acknowledgements}

The authors are grateful to the Ministry of Public Works for granting permission to use the wastewater inflow data and to the Metrological Department of the Directorate General of Civil Aviation for providing the relevant temperature and rainfall datasets. This work was supported by Kuwait University, Research Grant No. EV01/10.

\section{References}

[1] Al-Ruwaih, F., and Almedeij, J. (2007). "The future sustainability of water supply in Kuwait." Water International, 32(4), 604-617.

[2] Al-Ruwaih, F., Shehata, M., and Al-Awadi, E. (2000). "Groundwater utilization and management in the state of Kuwait." Water International, 25(3), 378-389.

[3] Al-Wazzan, Y., and Al-Modaf, F. (2001). "Seawater desalination in Kuwait using multi-stage flash evaporation technology-historical overview." Desalination, 134, 257-267.

[4] Alhumoud, J. M., Behbehani, H.S., and Abdullah, T.H. (2003). "Wastewater reuse practices in Kuwait." The Environmentalist, 23, 117-126.

[5] Brockwell, P.J., and Davis, R.A. (2002). Introduction to Time Series and Forecasting, Springer, New York. 